\title{
Responsabilidad civil y administrativa del administrador de propiedad horizontal: normativa legal en Colombia'
}

\author{
Responsibility civil and administrative liability of the horizontal property manager: legal \\ regulations in Colombia
}

María Victoria Pérez Lopera² - Orlando de Jesús Valbuena Sossa ${ }^{3}$

\section{Resumen}

Conforme a la responsabilidad que debe asumir el administrador de propiedad horizontal, cuando se postula y acepta dicho cargo, éste se convierte en una de las autoridades más representativas en el régimen de propiedad horizontal en Colombia, para lo cual, la metodología a aplicar está basada en la descripción de fenómeno a través del análisis del parágrafo 2 del artículo 50 de la ley 675 de agosto 3 de 2001, con el objetivo de garantizar el ejercicio efectivo, ajustado a la normativa que legisle el Estado y que reglamente los requisitos del perfil idóneo y profesional que debe tener la persona que ocupe tan importante cargo de Administrador de Propiedad Horizontal en Colombia.

Palabras claves: Idoneidad, Perfil, Propiedad Horizontal, Regulación, Responsabilidad.

\section{Abstract}

Based on the fact that the administrator becomes one of the most representative authorities in the horizontal property regime in Colombia, the methodology to be applied is based on the description of the phenomenon, through the analysis of paragraph 2 of article 50 of the law. 675 of August 3, 2001, in order to guarantee the effective exercise and adjusted to the norm with the requirements of the professional and suitable profile that the person who applies to occupy the position of Horizontal Property Administrator in Colombia must have.

Keywords: Suitability, profile, Horizontal Property, Regulation, Responsibility.

\footnotetext{
${ }^{1}$ Artículo derivado del trabajo de grado de la de la Especialización en Derecho Administrativo titulado "Responsabilidad civil y administrativa del administrador de propiedad horizontal: normativa legal en Colombia".

${ }^{2}$ Abogada de la Corporación Universitaria Americana. Estudiante de Especialización en Derecho Administrativo de la Corporación Universitaria Americana. Mail: vickyperez87@hotmail.com

${ }^{3}$ Tecnólogo en salud ocupacional del SENA, Abogado de la Corporación Universitaria Americana, Estudiante de la Especialización en Derecho Administrativo de la Corporación Universitaria Americana. Estudiante Mail:valbuenaorlando0515@ coruniamericana.edu.co
} 


\section{Introducción}

La importancia del presente proyecto sólido que el Estado durante 20 años de la expedición de la ley 675 de 2001, no ha determinado un reglamento tal cómo lo indica el parágrafo 2 del artículo 50 de la mencionada ley, y dar por terminado el vacío existente que debe ser colmado con el fin de garantizar que la legislación Colombiana cumpla con su función primaria de regular el régimen de la administración de propiedad horizontal, a fin de alcanzar a sustentar dicho vacío y de manera que garantice una transparencia administrativa y la responsabilidad jurídica y operativa que figura actualmente en cabeza los propietarios residentes en unidades $\mathrm{PH}$.

Con la necesidad de analizar la idoneidad y el perfil que se debe de exigir a las personas que ejerzan el cargo de administradores, su perfil idóneo sea regulado normativamente, así mismo, como los requisitos para ejercer dicho cargo, dado que frecuentemente en la cotidianidad, se evidencian los innumerables riesgos que se han venido generado a través de todos estos años, donde los copropietarios de los inmuebles, ven cada vez más el riesgo y el menoscabo su patrimonio que los amenaza a responder de manera social, administrativa, financiera, económica, ambiental y penal ante los riesgos jurídicos permanentes, por no tener el administrador un perfil idóneo, que lo responsabilice ante las implicaciones y consecuencias legales de sus actos y que finalmente como ya lo habíamos, se arriesgan los activos o inmuebles de los copropietarios.

Por lo descrito en el párrafo anterior y partiendo desde esta perspectiva en materia investigativa de manera específica, podemos destacar algunos estudios doctrinarios que se han realizado desde una metodología de enfoque Cualitativo el cual tiene como objeto, afirmar y resolver la presente investigación.

\section{Metodología}

Con base en que el administrador se convierte en una de las autoridades más representativas en el régimen de propiedad horizontal en Colombia, la metodología a aplicar, está basada en la descripción de fenómeno, a través del análisis del parágrafo 2 del artículo 50 de la ley 675 de agosto 3 de 2001, como material jurídico y doctrinal existente en torno al tema de la propiedad horizontal, aunado a lo anterior, es necesario enunciar, que la presente investigación se basa en fuentes primarias referentes a los datos obtenidos a través de que los expositores de este texto son ciudadanos que viven en propiedad horizontal y pertenecen a las asambleas de los conjuntos residenciales, están relacionados con las actuaciones cotidianas, los sucesos y así mismo, con las consecuencias derivadas de las decisiones de los administradores de propiedad horizontal, que finalmente repercuten en multas y hasta en poner en riesgo del patrimonio de los copropietarios. Es así que, además de conocer cuál es la misión de los que gerencian y administran las unidades residenciales; y fuentes secundarias teniendo de base la normativa actual, existe un vacío con respecto al perfil idóneo que se debe exigir al administrador, el cual es responsable de administrar los patrimonios y de velar por la seguridad de éste, además, que tenga la capacidad de guardar por el cumplimiento de la ley, los reglamentos, las decisiones tomadas por la Asamblea General de Copropietarios y demás situaciones que surjan.

Se realiza el presente texto haciendo uso de una metodología con enfoque cualitativo con alcance descriptivo mediante tres fases:

Fase 1: Heurística que corresponde a la identificación de las fuentes de información más sobresalientes se basará en fuentes primarias referentes a los datos obtenidos a través de entrevistas a ciudadanos y profesionales que tiene relación y conviven en régimen de propiedad horizontal, asisten a las asambleas y discuten temas de las administraciones 
de los edificios, como fuentes secundarias provenientes de interpretaciones ya elaboradas por teóricos, doctrinantes, leyes existen, textos, diccionarios, artículos, demás documentos que se basan en la propiedad horizontal, pisos en el sistema Europeo como elemento de estudio.

Fase 2: Hermenéutica, que corresponde a la selección e interpretación de la información de acuerdo con las fuentes consultadas, donde se tuvo en cuenta el régimen de propiedad horizontal o ley 675 de 2001, en donde despliegan vacíos que generan conflictos entre los administradores y copropietarios, entre los mismos copropietarios residentes en las unidades residenciales; por tal razón la Corte Constitucional, ha adoptado el papel del legislador al llenar esos vacíos con jurisprudencia, situación que evidencia la necesidad de que el Gobierno Nacional ajuste y modifique la ley actual, toda vez, que al encontrarse en ellas problemáticas que se han evidenciado en los últimos 20 años de vigencia de la norma, pero no se ha tenido en cuenta la el perfil, la idoneidad y la formación que debe tener un administrador que se responsabiliza de ejercer, gerenciar y gestionar la administración de la propiedad horizontal.

Fase 3: Análisis de la información de los principales hallazgos con la técnica escogida para ejecutar el presente proyecto de investigación con el propósito de ajustar el perfil profesional y la eficacia del administrador de propiedad horizontal, mediante el cual, se manifiesta la necesidad de darle aplicación al parágrafo 2 del artículo 50 de la ley 675 de agosto 3 de 2001 y de reglamentar el perfil de los administradores de $\mathrm{PH}$ y se presente resultado por parte del Estado en donde jurídicamente se exija el perfil idóneo profesional para la actividad de administrador de $\mathrm{PH}$.

\section{Desarrollo}

Como se indicó en este proyecto el desarrollo de la acreditación de la idoneidad al cargo de administrador de la propiedad horizontal que tuvo sus inicios en el contenido de la ley 675 de 2001, a fin de facilitar el marco profesional del perfil y su formación para ejercer el cargo de administrador.

Poder tener una buena representación y la defensa de las comunidades de propiedad horizontal ante los diferentes conflictos que puedan surgir entre los residentes, y en especial en aquellos supuestos en que su comunidad de propietarios necesite los servicios de administradores que tenga la formación idónea e integral que se requiere para cumplir con el perfil de Administrador de Propiedad Horizontal.

Sobre este tema existen muchos vacíos, a la vez riesgos de toda índole, pues una persona que no tiene la formación adecuada para gerenciar y administrar una unidad residencial, puede llegar a tomar decisiones erróneas, al desconocer los lineamientos que representan para la persona jurídica multas o procesos en los cuales terminan pagando los copropietarios, es decir, como producto de malas actuaciones y contrataciones, como es el caso y ejemplarizando de indemnizaciones, cierre de piscinas, o establecimientos de comercio, por los riesgos tecnológicos sociales y naturales y también por la falta de ser previsible o cauteloso en la planeación y prevención de daños jurídicos en la obtención de pólizas que aseguren los bienes de los copropietarios.

Las actuaciones que se adelanten en relación de la administración de propiedad horizontal se tramitarán de acuerdo con los principios y el procedimiento establecido en el Código Contencioso Administrativo, en cuanto las actuaciones administrativas se desarroIlarán con arreglo a los principios de economía, celeridad, eficacia, imparcialidad, publicidad y contradicción y, en general, conforme a las normas del ART 3, de la Ley 1437 de 2011, sus trece (13) numerales, en concordancia con los artículos 1, 2, 3, 4, 5, 6, 13, 29, de la Carta Magna, C.N, entre otros. En particular, se debe garantizar el principio constitucional del de- 
bido proceso, buena fe y favorabilidad. Las pruebas requeridas serán sumarias, deben ser garantizadas en la solicitud de registro, sea decidida en el menor tiempo posible, en el marco de un trámite administrativo ágil y expedito, en el cual el administrador debe ocuparse de defender los intereses de las comunidades de propietarios para el debido cumplimiento del régimen establecido por norma legal de la propiedad horizontal, así como preservar los deberes y derechos que se adquieren por la propiedad, en el momento de contratar a un administrador, se debe tener en cuenta la Ley 675 de 2001, esta gran responsabilidad recae en el consejo de administración.

En toda actuación administrativa en la cual tengan interés los copropietarios tienen derecho a obtener respuesta oportuna y eficaz en los plazos establecidos para el efecto, a aportar documentos u otros elementos de prueba, a que dichos documentos sean valorados y tenidos en cuenta al momento de decidir.

Por lo anterior, se debe entonces buscar un administrador con perfil gerencial, ejecutivo, con capacidades de dirección y administración de recursos humanos, además de conocimientos específicos en contabilidad y administración de propiedad horizontal, manejo y liderazgo de comunidades, amplio conocimiento del régimen laboral y de la legislación de propiedad horizontal, solución de conflictos, entre otro, por lo tanto forman parte del núcleo esencial de derechos como la intimidad o la autonomía privada, sobre los cuales se admiten excepciones cuando entran en conflicto con los derechos de los demás o el orden jurídico. A contrario sensu, los derechos que trascienden ese espacio íntimo pueden ser objeto de regulación más amplia, siempre bajo los parámetros que imponen los principios y valores del ordenamiento constitucional.

Podríamos decir que, dentro de las aptitudes y actitudes del Administrador de propiedad horizontal, figuran como las más importantes, habilidades de comunicación escrita y oral, empatía, Integridad, fiabilidad, paciencia y honestidad, habilidad para reclutar personal competente acorde a las necesidades que se requieren; capacidad para encontrar colaboradores y proveedores dignos de confianza, capacidad de mediación en la resolución de los conflictos, dedicación.

\section{Conclusiones}

Es imprescindible que el Estado legisle para poder sancionar el incorrecto proceder ético y moral de quien desempeña las funciones como administrador de propiedad horizontal, toda vez que, muchos copropietarios se encuentran actualmente muy perjudicados porque el Estado, hasta tanto, no decida expedir dicha normativa, los riesgos y las consecuencias de las malas decisiones y actuaciones de los administradores propiedad horizontal, en riesgo el patrimonio de los copropietarios.

Los administradores deben cumplir con las características del perfil y de idoneidad que defina el Legislador, para prevenir sobrecostos en temas laborales, administrativos, económicos por diferentes conceptos tales como por indemnizaciones y multas a que haya lugar en un momento determinado y por malas decisiones que haya tomado el administrador por acción u omisión que por desconocimiento, no lo debe eximir de ninguna responsabilidad del peso de la ley.

Se debe hacer un aclamado llamado al órgano legislativo colombiano para que observe la necesidad de responsabilidad y expida y sancione una nueva ley que sanee los vacíos que las leyes anteriores dejaron, a través de una norma mediante la cual se pueda tener claridad de aspectos claves y necesarios del perfil idóneo de la persona que administre las propiedades horizontales. 


\section{Bibliografía}

Acevedo, U. C., \& Piedrahíta, N. (2016). Régimen de Propiedad Horizontal en Colombia: Estudio del alcance de la Ley 675 de 2001 y su eficacia frente a la relación entre copropietarios y administrador a 2016 (Trabajo de pregrado). Universidad de San Buenaventura, Medellín, Colombia. Obtenido de: http://bibliotecadigital.usb.edu.co/bitstream/10819/3341/1/Regimen_Propiedad_Horizontal_Piedrahita_2016.pdf

Asamblea Nacional Constituyente. (1991). Constitución Política de la República de Colombia de 1991. Obtenido de: https://www.alcaldiabogota.gov.co/sisjur/normas/Norma1. jsp?i=4125

Burgos Díaz, M. C. y Ochoa Padilla, Y. M. (2020). Normatividad aplicable a propiedad horizontal en Europa caso: España y América Latina caso: Colombia (Trabajo de pregrado). Universidad Cooperativa de Colombia, Montería, Córdoba, Colombia. Obtenido de: https://repository.ucc.edu.co/bitstream/20.500.12494/20499/1/2020_normatividad_aplicable_propiedad.pdf

Congreso de Colombia. (2001). Ley 675 de 2001. Obtenido de: http://www.secretariasenado.gov.co/senado/basedoc/ley_0675_2001.html

Congreso de Colombia. (2011). Ley 1437 de 2011. Obtenido de: http://wsp.presidencia.gov. co/Normativa/Leyes/Documents/ley143718012011.pdf

Congreso de Colombia. (2001). Ley 675 de 2001. Obtenido de: https://actualicese.com/ley675-de-03-08-2001-ii-parte/

EINotariado.com. (2004). Copropiedad: consejos de administración sí pueden nombrar administradores: Corte Constitucional. Obtenido de: https://www.elnotariado.com/ copropiedad-consejos-administracion-pueden-nombrar-administradores-corte-constitucional-1872.html

Gerencie.com. (2020. Propiedad horizontal en Colombia. Obtenido de: https://www.gerencie.com/propiedad-horizontal.html

Ruiz Muñoz, D. C. (2014). Análisis del régimen de propiedad horizontal en Colombia. (Trabajo de pregrado). Universidad Libre, Bogotá, Colombia. Obtenido de: https://repository.unilibre.edu.co/bitstream/handle/10901/7726/RuizMunozDianaCarolina2014.pdf;jsessionid=2C59566F00F535A30E7836ECC75B9AB3;jsessionid=2C59566F00F535A30E7836EC C75B9AB3?sequence $=1$ 